\title{
Faded shine.... The degradation of brass powder in two nineteenth century paintings
}

\author{
Ester S B Ferreira ${ }^{1 *}$, Danièle Gros ${ }^{1}$, Karin Wyss ${ }^{1}$, Nadim C Scherrer ${ }^{1,2}$, Stefan Zumbühl ${ }^{2}$ and Federica Marone ${ }^{3}$
}

\begin{abstract}
During the examination of two 19th century oil paintings by Swiss artists, the Reading pastor (ca. 1885) by Ferdinand Hodler (1853-1918) and Portrait of a young girl (ca. 1888) by Filippo Franzoni (1857-1911), it was observed that in particular locations, the surface had an unusually granular texture, given by the application of metallic particles and the presence of large translucent green agglomerates. In this paper we investigate the composition and origin of the metal particles and green agglomerates. A combination of bulk analysis (GC-MS and FTIR) and analytical microscopy techniques (X-ray tomographic microscopy, light microscopy, ATR-FTIR-FPA imaging and SEM-EDX) were used. It was concluded that the metal particles are composed of a lower quality brass (copper/zinc alloy) and ground from foil. The current appearance resulted from the reaction of the brass and its corrosion products with the fatty acids in the surrounding paint/varnish matrix. This has lead to the formation of agglomerates of zinc and copper carboxylates, the latter responsible for their green colour.
\end{abstract}

Keywords: Metallic pigment, Brass, Oil, Copper carboxylates, Zinc carboxylates, Synchrotron radiation X-ray tomographic microscopy, SEM-EDX, ATR-FTIR-FPA imaging, Dezincification

\section{Introduction}

The painting Reading pastor painted ca. 1885 by Ferdinand Hodler (1853-1918) represents a three quarter portrait of a pastor reading a book which he holds close to the chest (Figure 1). The scene has as the main light source a window behind the left shoulder of the pastor, covered by a semi translucent curtain. Surface observation with a stereomicroscope showed that a combination of metallic particles and green agglomerates were present in areas where increased luminosity is to be expected, where the light originates and where upon it falls: e.g., the curtain, the pastor's earlobe and the table (Figure 2).

In the case of the Portrait of a young girl by Franzoni (Figure 3) dated from ca. 1888, the metal powder was used in a less pictorial way and could only be seen, under closer observation with a stereomicroscope, used sparingly in the background paint. It is important to mention that two factors hindered the clear visualization of the distribution of metal particles in the painting by

\footnotetext{
*Correspondence: ester.ferreira@sik-isea.ch

${ }^{1}$ Analytical Laboratory, Art Technology Department, SIK-ISEA, Swiss Institute for Art Research, Zollikerstrasse 32, 8032 Zurich, Switzerland Full list of author information is available at the end of the article
}

Franzoni: on the one hand, Franzoni himself had extensively reworked his painting (no longer using metal powder but rather conventional pigment mixtures) partially covering the paint layers containing the metal powder. On the other hand, during a later restoration intervention, significant areas of the background were overpainted. Where visible, the metal particles were closely associated with the green agglomerates (Figure 4), as had been observed in the painting by Ferdinand Hodler.

\section{Experimental}

In the case of the Reading Pastor one sample was analysed by synchrotron radiation X-ray tomographic microscopy (SRXTM).

In both the Reading pastor and Portrait of a young girl, the combined non-invasive, bulk and analytical microscopy techniques were used. When justified, samples were taken and materials analysed by gas chromatography mass spectrometry (GC-MS) and/or Fourier transform infrared spectroscopy (FTIR) or cross-sections prepared and studied by analytical microscopic techniques [light microscopy (LM), scanning electron microscopy coupled with energy dispersive X-ray spectroscopy (SEM-EDX),
Chemistry Central

(c) 2015 Ferreira et al. This article is distributed under the terms of the Creative Commons Attribution 4.0 International License (http://creativecommons.org/licenses/by/4.0/), which permits unrestricted use, distribution, and reproduction in any medium, provided you give appropriate credit to the original author(s) and the source, provide a link to the Creative Commons license, and indicate if changes were made. The Creative Commons Public Domain Dedication waiver (http://creativecommons.org/ publicdomain/zero/1.0/) applies to the data made available in this article, unless otherwise stated. 
and ATR-FTIR-FPA imaging]. Setup and instrumental parameters are given in the "Methods" section and details of the analytical results are given in Tables 1 and 2.

\section{Results and discussion}

Reading pastor by Ferdinand Hodler (private collection)

A sample (which separated into three subsamples during sampling) was collected from an area affected by the degradation phenomena in the lower left edge of the painting illustrated in Figure 2. Details of the analytical findings are given in Table 1.

\section{Synchrotron radiation X-ray tomographic microscopy (SRXTM)}

The first subsample $\left(234 \times 167 \mu \mathrm{m}^{2}\right)$ was studied using SRXTM. The study of paint samples using SRXTM brings information on the three dimensional distribution of phases of interest in an unmanipulated paint sample [1]. The reconstructed data provided a cube of 8-bit grey scale images with a pixel size of $370 \mathrm{~nm}$. The grey level of each phase depends on its absorption and scattering interaction with the X-ray beam and therefore on composition. Segmentation based on grey scale level allows the visualization of the distribution in three dimensions of each phase in the context of the entire sample. This approach has proved extremely useful in the study of reactivity in paintings [2] and has uniquely allowed the study of porosity properties in 19th century ground layers [3].

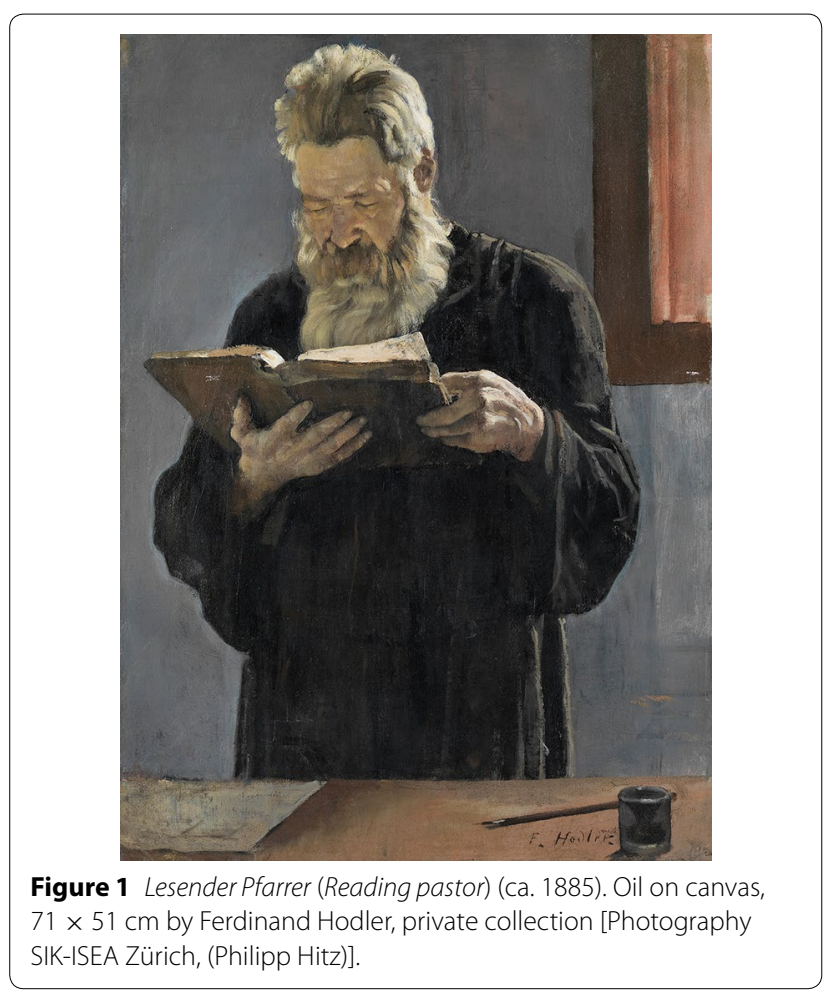

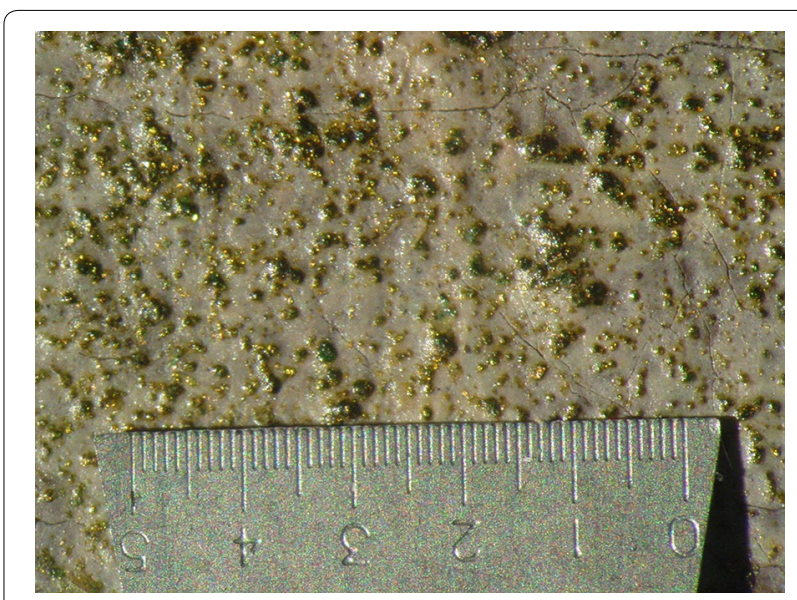

Figure 2 Reading pastor (ca. 1885) by Ferdinand Hodler. Detail of the lower left edge of the painting (smaller scale division $100 \mu \mathrm{m}$ ) [Photography SIK-ISEA Zürich, (Danièle Gros)].

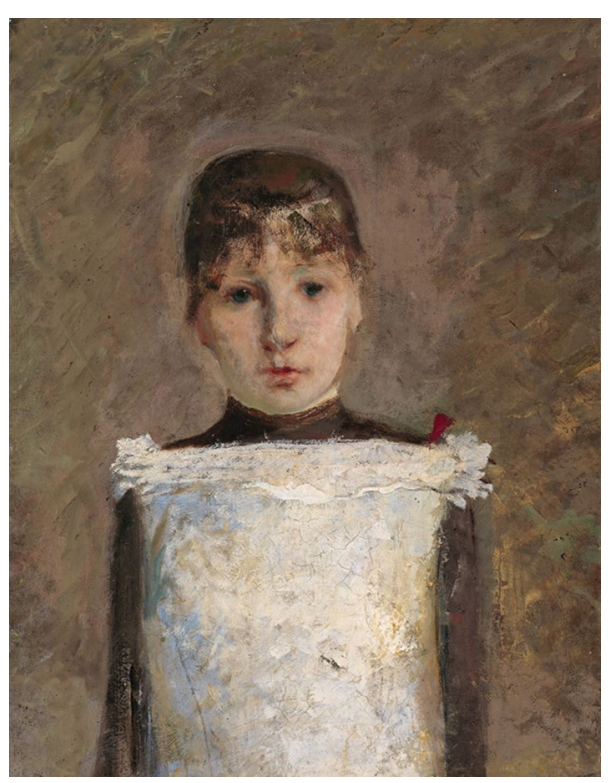

Figure 3 Ritratto di giovane ragazza (Portrait of a young girl) (ca. 1888). Oil on canvas, $59 \times 46 \mathrm{~cm}$ by Filippo Franzoni. (Fondazione Filippo Franzoni, Locarno, Switzerland) [Photography SIK-ISEA Zürich, (Philipp Hitz)].

In the present case we have focused on the three phases of interest: the metal particles, the paint and the green agglomerates. In Figure 5, a light microscopic image of the sample (Figure 5a) and the reconstruction of the distribution of the phases of interest are shown (Figure 5b, c). On the sample surface four distinct green agglomerates can be identified. At the core of the green agglomerates, the metallic pigment particles can be observed. 


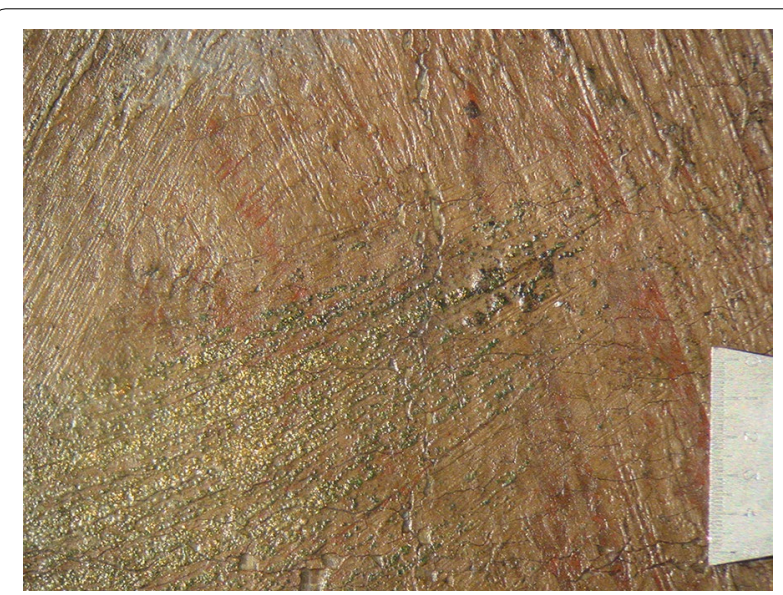

Figure 4 Portrait of a young girl (ca. 1888) by Filippo Franzoni. Detail of the upper right area of the painting (smaller scale division $100 \mu \mathrm{m}$ ) [Photography SIK-ISEA Zürich (Danièle Gros)].

The thin, elongated and folded morphology of the particles suggests these originate from a metallic foil. The fragments have a thickness varying from 1-4 $\mu \mathrm{m}$. The study of the virtual cross sections (Figure 6a, b) extracted from the tomographic dataset provide further information. A first observation is that the sample is composed of two paint layers of different X-ray linear attenuation coefficient. Above the paint surface and only there, not mixed with the paint, are elongated, flat and highly attenuating particles, as expected from metal foil fragments. These metal fragments are embedded in lower absorbing masses contained in the varnish layer. Ferdinand Hodler applied the metal not embedded in the paint, but mixed within the varnish layer.

\section{Analytical microscopic study of a sample in cross section}

A cross section of a second microsample collected from the same location as the one studied by SRXTM was prepared.

LM and SEM-EDX analysis of the cross section surface confirmed that the metallic particles were brass with a copper to zinc ratio of approximately 85:15. Element mapping using SEM-EDX detected chlorine associated with the metal particles in particular but also with the surrounding environment and the paint in general. Detailed backscattered electron images (SEM-BSE) of the brass foil suggested surface pitting of the alloy (Figure 7a). Clear interpretation of the origin of the metal foil surface structure requires higher magnification than the current $10000 \times$. Higher magnification images of the metal surface could not be obtained possibly due to insufficient surface quality as a result of micromesh dry polishing.

The brass of the composition found in the painting by Hodler is described as malleable and ductile [4] but is not the highest quality brass as used as gilding metal which has a higher copper content (95:5 $\mathrm{Cu}: \mathrm{Zn})$ [5]. Element analysis using SEM-EDX detected chlorine associated with the metal particles which is compatible with the use of sodium chloride as an aid in the grinding process of the metal foil. The use of salt as grinding agent has been mentioned in literature dealing with Rococo and Baroque techniques [4]. The same source mentions that this method is more suited to the preparation of gold and silver pigment. In the case of copper containing alloys and, in order to avoid corrosion, grinding without salt is recommended, indicating that the corrosion acceleration in the presence of chlorine had been known.

ATR-FTIR-FPA imaging of the cross sections confirms that the green agglomerates are composed of copper and zinc soaps and shows that the distribution of the two types of soaps is not identical. Although the signal was relatively noisy, it could be concluded, based on spectral comparison in different regions, that areas of the soap agglomerate on the upper side of the metal leaf are richer in zinc carboxylates as suggested by the mapping of the $1540 \mathrm{~cm}^{-1}$ (zinc carboxylates) and $1585 \mathrm{~cm}^{-1}$ (copper carboxylate) peaks (Figure 8). Interestingly, an enrichment in lead carboxylates of the lower area of the aggregate can be seen in the $1525 \mathrm{~cm}^{-1}$ peak intensity distribution (Figure 8c). This component originates, most likely, from the reaction of the lipids in the paint/ varnish matrix and the lead white in the paint layer [6].

\section{Bulk analysis (FTIR and GCMS)}

The single point analysis of the varnish layer in the painting by Ferdinand Hodler in an area where the metal pigment had been applied, showed evidence of the presence of lipids suggesting that the pigment would have been dispersed in oil prior to application.

The green agglomerates were composed of a combination of copper and zinc carboxylates (single point FTIR spectra compared with reference compounds and published spectral library [7]) of saturated fatty acids with a minor content on diacids (GC-MS), indicating that the green mixture of copper/zinc soaps resulted from the reaction between saturated fatty acids of the binding medium the metal pigment was applied with or, from the paint layer below and the copper and zinc of the brass powder originally used by Hodler.

In the case of Reading pastor two factors play a role in the reactivity of the brass pigment. On the one hand the presence of chlorine and on the other the high content in zinc. The presence of highly mobile anions such as chloride are known to accelerate the corrosion process $[8$, 9]. Brasses with substantial amounts of zinc (above 15\%) become destabilized and lose zinc by dezincification [10] with a preferential initial formation of zinc corrosion 


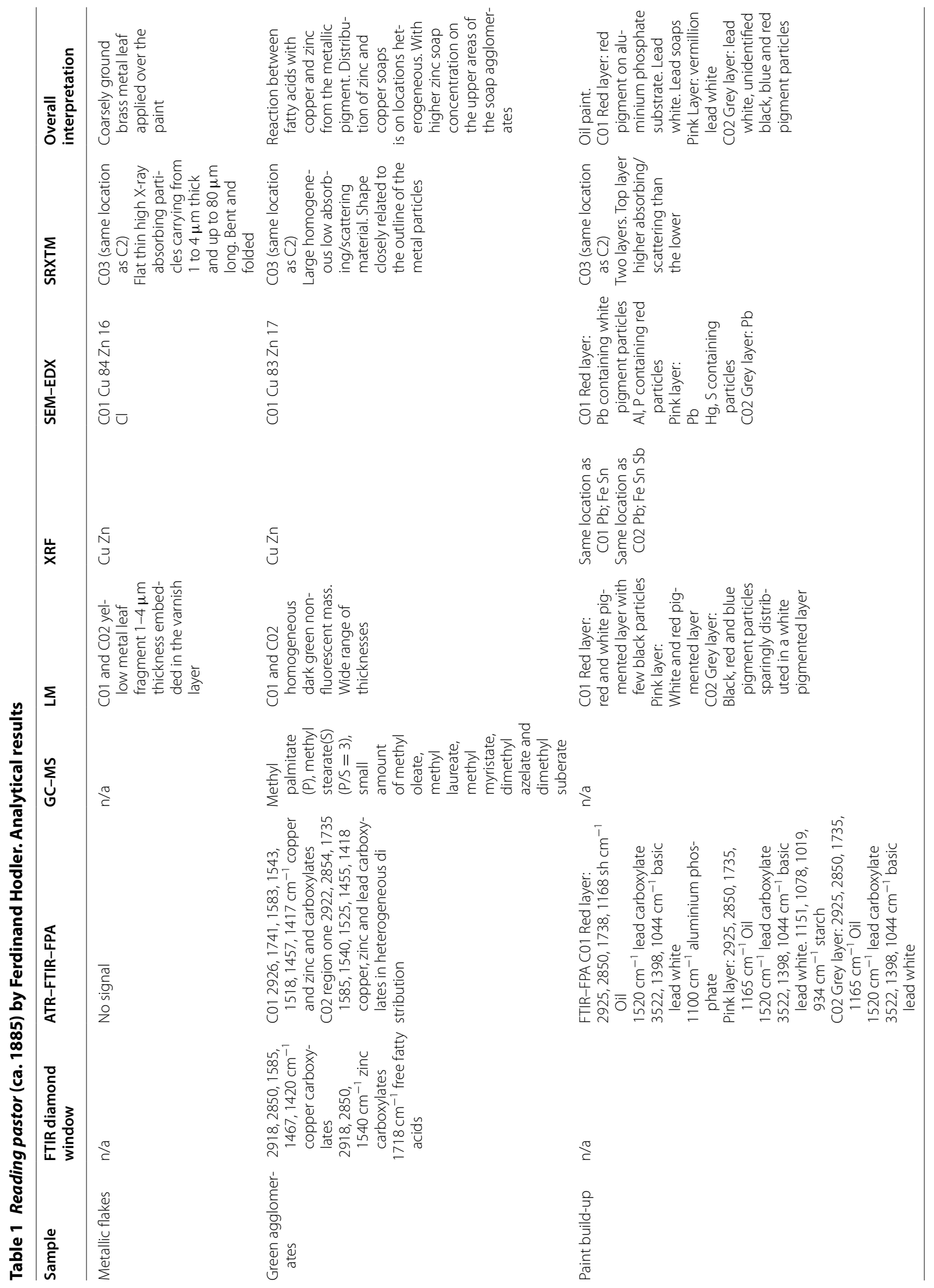




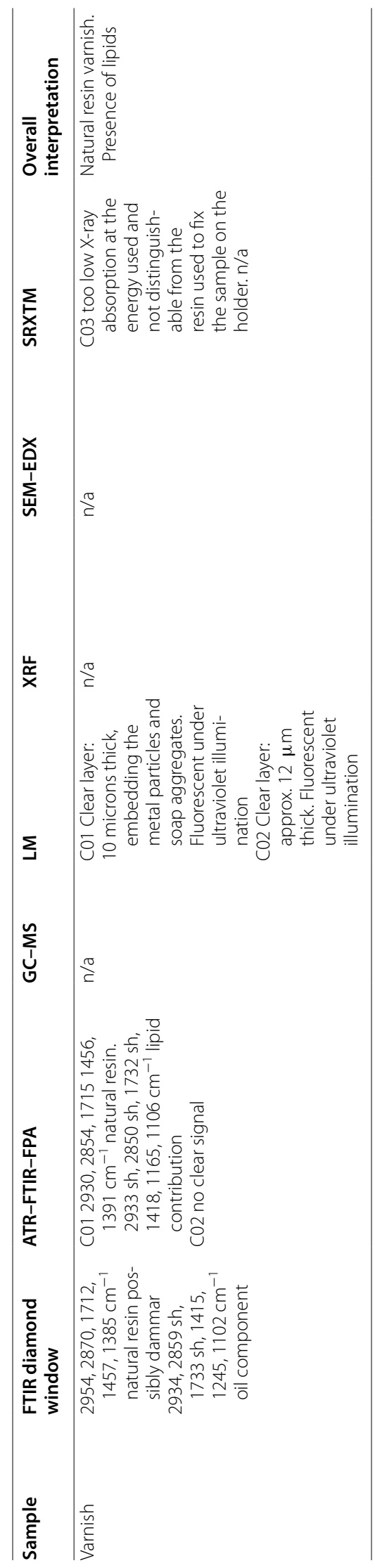




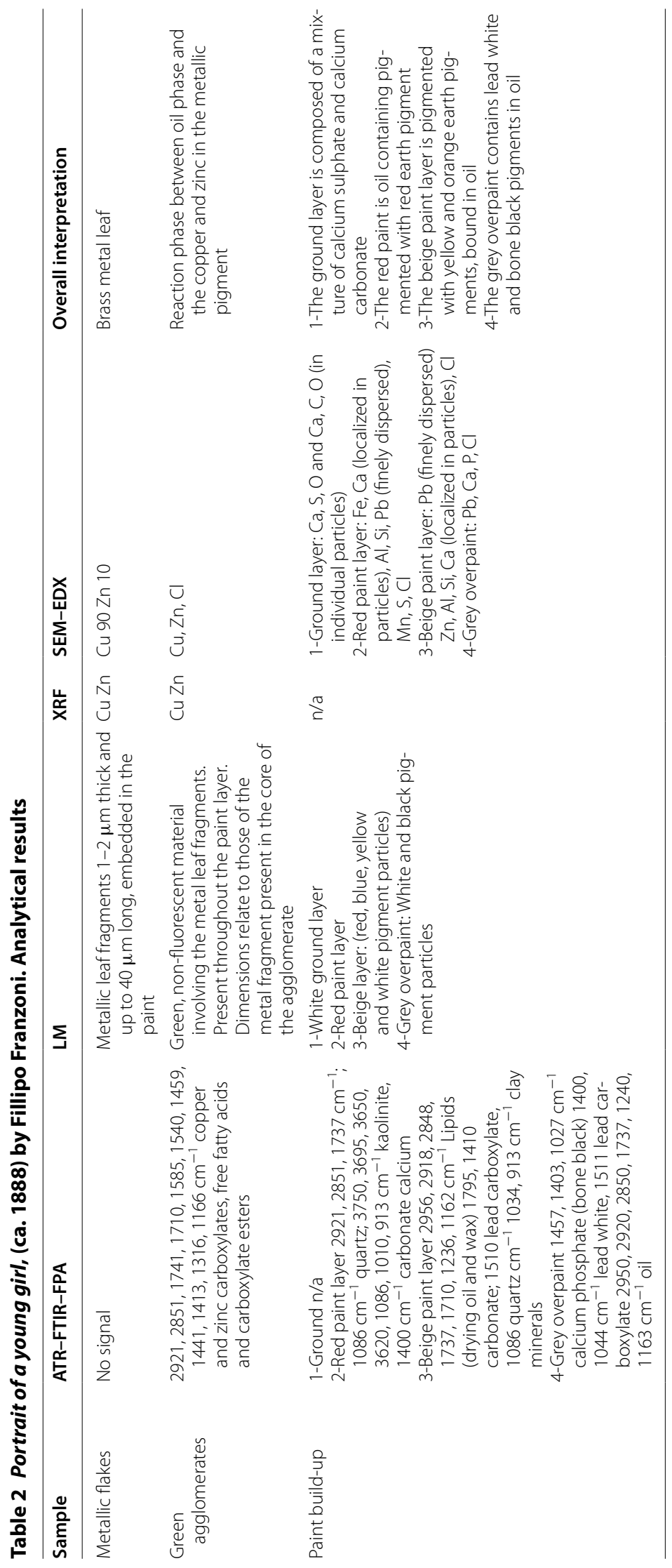




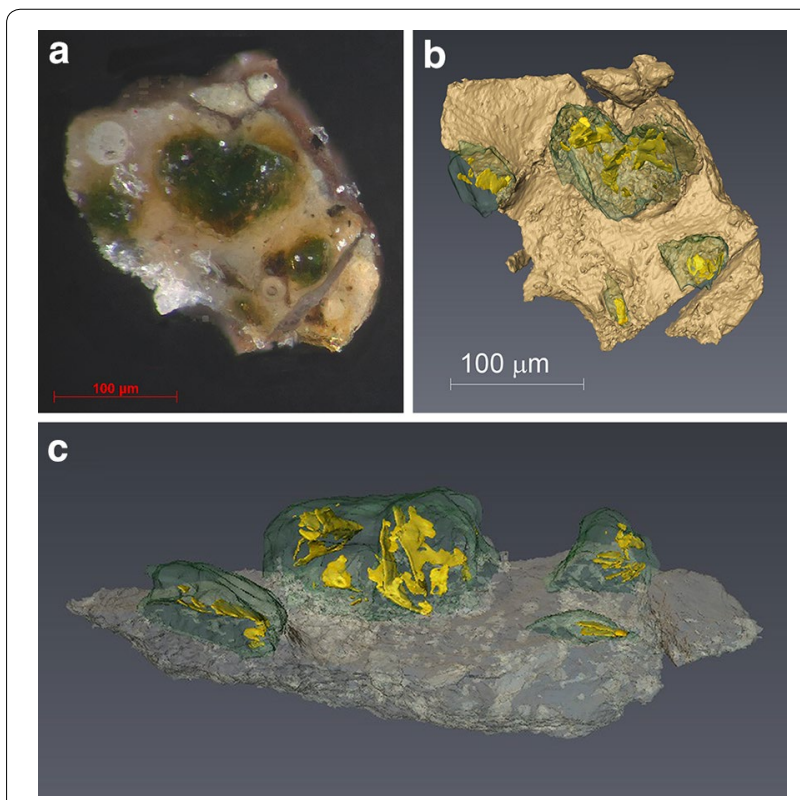

Figure 5 a Light microscopy image of a sample taken from the lower left edge of the painting Reading pastor (1885) by Ferdinand Hodler. $\mathbf{b}$ Top view and $\mathbf{c}$ side view of SRXTM data reconstructing the sample surface and showing the distribution of the metal foil in the core of the soap agglomerate.

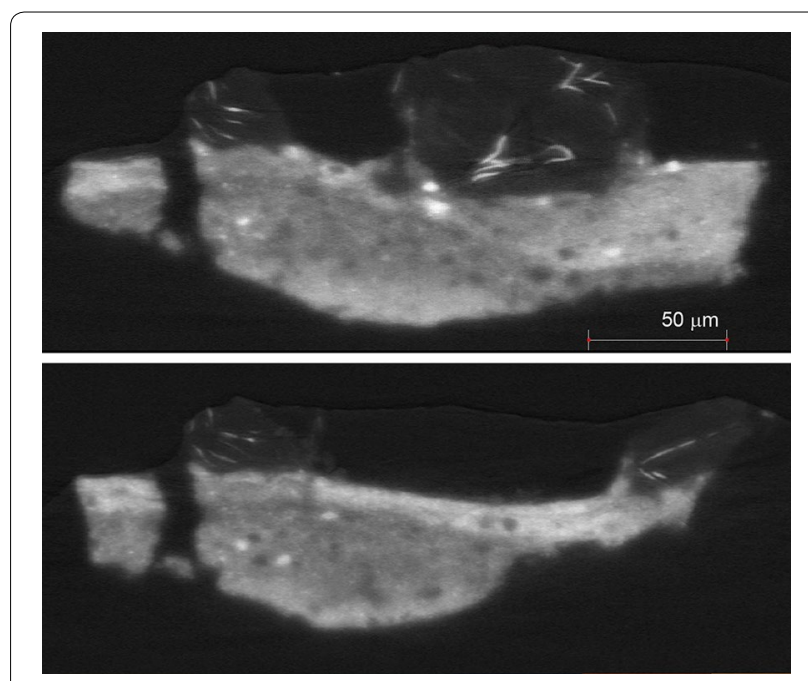

Figure 6 Virtual cross sections extracted from SRXTM data.

products. The heterogeneous distribution of zinc and copper soaps in the agglomerates and the structure of the metal foil surface could be suggestive of dezincification of the brass alloy prior to the formation of soaps.

\section{Portrait of a young girl by Filippo Franzoni}

This painting (Figure 3) was heavily retouched and had been wax resin relined. The sampling strategy and
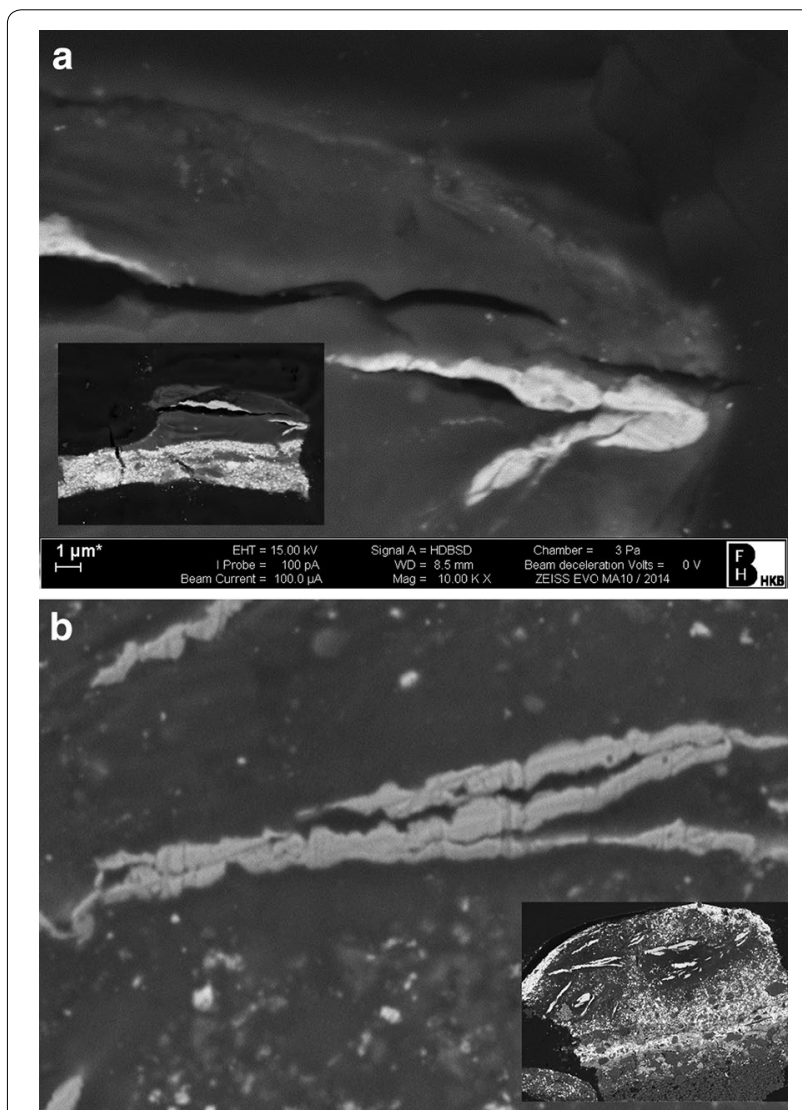

Figure 7 SEM-EDX images ( $\times 10000$ magnification) of the brass pigment surface in the cross sections of the samples collected from a Reading pastor by F. Hodler and $\mathbf{b}$ Portrait of a young girl (1888) by F. Franzoni. The rough and pitted nature of the metal foil surface could be due to a dezincification corrosion process.

analysis was limited to the characterization of metallic pigment application and characterization of the agglomerated composition. One sample was collected and a cross-section prepared (Figure 9a). Detailed chemical profiling of the binding medium was not carried out as it would have been severely compromised due to the presence of the lining material.

The analytical results that allow the characterization of the build-up are given in detail in Table 2. In the painting by Franzoni, the metal pigment (characterized as a $\mathrm{Cu}: \mathrm{Zn}$ 90:10 brass by SEM-EDX) was applied mixed with the beige oil paint of the background. The brass pigment and the reaction phases are well embedded in the paint and not on the surface as observed before in the painting by Ferdinand Hodler. The brass fragments are typically $1-2 \mu \mathrm{m}$ thick and up to $40 \mu \mathrm{m}$ long. No chlorine was detected, suggesting a different preparation method for the pigment.

The distribution of zinc and copper soaps is also heterogeneous with increased signal from zinc carboxylates 

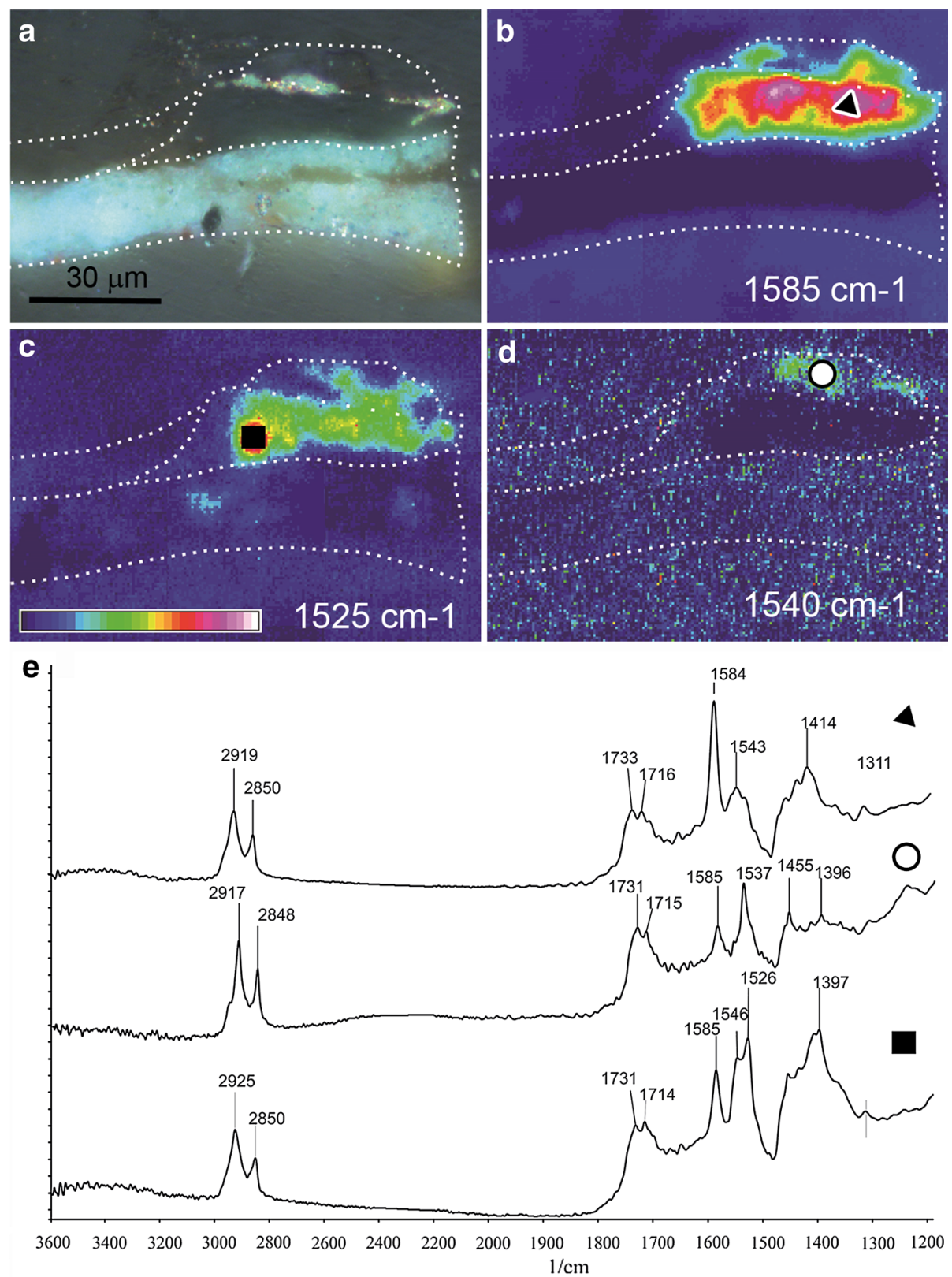

Figure 8 Analytical microscopic analysis of the cross section of a sample taken from the lower left edge of the painting Reading pastor (1885) by F. Hodler: a light microscopy image in bright field mode with cross polarization, b-d ATR-FTIR-FPA distributions of different phases, e ATR-FTIR spectra of selected regions.

in the outer rim of the agglomerate and from copper carboxylate in the core region (Figure 9d). The presence of zinc in the paint matrix, even if at a very low level, hinders the further meaningful interpretation of the metal soap distribution data. Detailed BSE images of the metal foil suggest progressing pitting corrosion (Figure 7b). The copper content of the brass pigment used by Franzoni was higher than that found in the painting by Ferdinand
Hodler but neither are of gilding metal quality (95:5). The technique used by Filippo Franzoni of mixing the brass pigment in oil paint might have promoted the formation of the zinc and copper soaps.

\section{Conclusions}

The pigment alteration phenomena observed in the paintings of Ferdinand Hodler and Filippo Franzoni can 

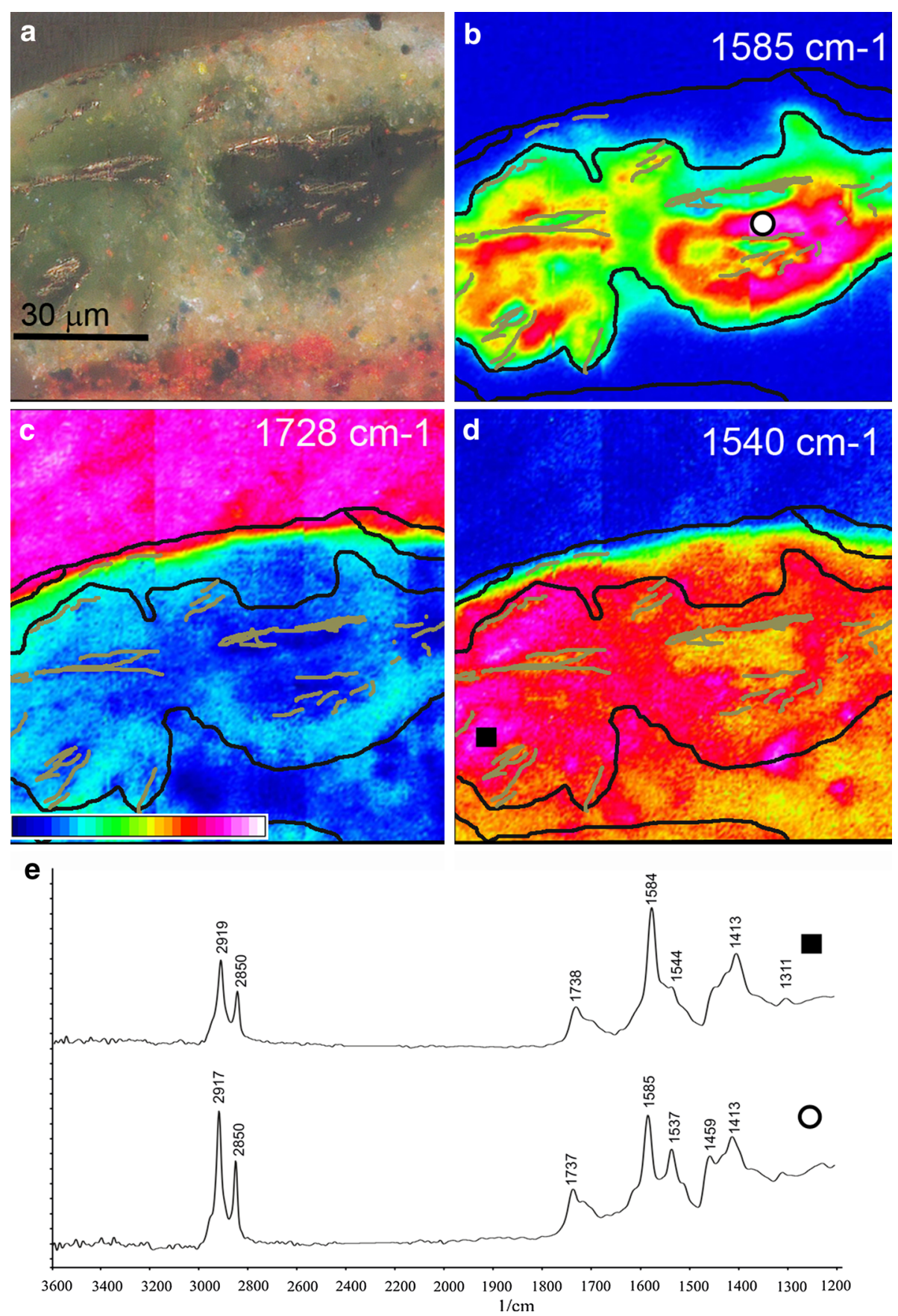

Figure 9 Analytical microscopic analysis of the cross section of a sample taken from the lower left edge of the painting Portrait of a young girl (1888) by F. Franzoni: a light microscopy image in bright field mode with cross polarization, b-d ATR-FTIR-FPA distributions of different phases, e ATR-FTIR spectra of selected regions.

be described as the formation of copper and zinc soaps at the surface of the brass pigment powder as a result of the reaction of the lipidic binding medium with the copper and zinc (or their oxidation products) brass components. The formation of blueish-green zinc and copper carboxylates in composite brass artefacts when the metal is in contact with lipid sources is known to artefact conservators $[11,12]$. Interestingly the conference Chemistry for Cultural Heritage that took place in 2014 in Vienna witness the report of the first two studies of metal brass 
use and degradation in paintings. The first study focused on an 18th century painting by Giovanni Antonio Pellegrini (1675-1741). In this painting the background was originally guilded with brass leaf and had been extensively overpainted. Studies of samples in cross section showed visible copper and zinc orgametallic masses surrounding the leaf [13]. The second example, reported here, addresses the unusual use and degradation of powdered brass pigment in late 19th century oil paintings on canvas.

The instability and reactivity of the brass particles disrupts the initial intention of the artists of bringing luminosity to the painting surface, by severely darkening and dulling it. Probably in the same year (ca. 1885), Ferdinand Hodler made a replica of this painting [Lesender Pfarrer (Reading pastor) ca. 1885, oil on canvas, $61.5 \times 49 \mathrm{~cm}$, SKKG Wintherthur, Switzerland] and interestingly no longer used brass but created luminosity by a different choice of pigments. In the case of the Portrait of a young girl, Franzoni himself extensively overpainted the areas where metal pigment had been used. Both these facts are possibly an indication that the alteration of the brass powder occurs soon after application.

The heterogeneous distribution of zinc and copper soaps within the agglomerates and the pitted structure of the edges of the brass pigment particles observed in the back scattered SEM images are suggestive of a progressing dezincification. Although a significant number of paintings from these two artists have been studied, very few other examples of use of metallic pigment powder have been described. It must be remarked, however, that the recognition of metallic powder pigment, in particular when corroded, can only be carried out by studying the surface of the painting at high magnification, preferably by an experienced user. It is thus possible that other cases might not have been recognized. Although the corrosion of copper alloys is well known in cultural heritage research, no description of the simultaneous formation of zinc and copper soaps in degradation of brass pigment used in easel oil paintings has been found in literature.

Our preliminary results suggest that the high instability already experienced by the artists themselves might be one reason for the rare use of this powder. The authors suggest that the presence of chlorine (possibly originating from the pigment preparation method) and the application of the pigment with the aid of an oil in the case of the painting by Ferdinand Hodler, and the embedding of brass particles in oil paint in the case of the painting by Franzoni, might accelerate the formation of copper and zinc soaps. It is hoped that the careful illustration and description of the brass pigment degradation presented here will serve as a comparing reference in future case studies.

\section{Methods}

Synchrotron radiation X-ray tomographic microscopy (SRXTM). The sample was attached to the sample holder with the aid of epoxy glue. The sample holder consists of a $32 \mathrm{~mm}$ long steel flat top rod, $500 \mu \mathrm{m}$ wide at the sample level, fixed onto an aluminium base. Microtomographic scans were performed at the Swiss Light Source (SLS) in Villigen (Switzerland) at the TOMCAT beamline [14]. For each tomographic scan, 1501 projections over $180^{\circ}$ were acquired (resulting in an angular step of $\left.0.12^{\circ}\right)$. For optimal contrast the energy was set to $22 \mathrm{keV}$ and the exposure time per projection was $1000 \mathrm{~ms}$. During measurement, the sample was cooled using a cryojet. Images were magnified using a $20 \times$ optical objective and digitized by CCD camera (PCO.2000) resulting in a pixel size of $0.37 \mu \mathrm{m}$. Tomographic reconstructions were computed using a highly optimized routine based on the Fourier transform method [15]. The reconstructed data cube of images was processed and analysed in the commercial software AVIZO 8.1.

Cross-section preparation: the sample is embedded in CEM4000 Lightfix (methylmethacrylate light curing embedding resin supplied by Cloeren Technology $\mathrm{GmbH}$ ) and polished, with the assistance of a sample holder, on micromesh sheets up to grade 12000.

Scanning electron microscope (SEM).The embedded samples are carbon coated (C-rod evaporation, Cressington 108) and analysed with a Zeiss EVO MA 10 VP scanning electron microscope equipped with SE and HDBSD detectors and an EDS system Thermo NORAN System 7 with a $30 \mathrm{~mm}^{2}$ SDD detector.

Fourier transform infrared spectroscopy (FTIR) was performed in a Perkin Elmer System 2000 Spectrometer in a diamond cell in transmission mode. Spectral range $4000-580 \mathrm{~cm}^{-1}$; resolution $4 \mathrm{~cm}^{-1} ; 256$ scans.

Attenuated total reflection Fourier transform infrared spectroscopy imaging coupled with a focal plane array detector system (ATR-FTIR-FPA imaging) was carried out in a Bruker Hyperion 3000 system with $64 * 64$ pixel FPA covering an area of $32 \times 32 \mu \mathrm{m}$.

\section{Authors' contributions}

ESBF: analytical strategy, data processing, analysis and interpretation. DG: research into historical, art technological and conservation context of the paintings. KW: GC-MS, FTIR. NCS: SEM-EDX. SZ: ATR-FTIR-FPA imaging. FM: synchrotron radiation $\mathrm{X}$-ray tomographic microscopy beamline support. All authors read and approved the final manuscript.

\section{Author details}

${ }^{1}$ Analytical Laboratory, Art Technology Department, SIK-ISEA, Swiss Institute for Art Research, Zollikerstrasse 32, 8032 Zurich, Switzerland. ${ }^{2}$ Art Technological Laboratory, Department of Conservation and Restoration, Bern University of the Arts - Bern University of Applied Sciences, Fellerstrasse 11, 3027 Bern, Switzerland. ${ }^{3}$ X-Ray Tomography Group, Swiss Light Source, Paul Scherrer Institute, WBBA/216, 5232 Villigen, Switzerland. 


\section{Acknowledgements}

The authors would like to thank Riccardo Carazzetti at the Servizi Cultural, Casa Rusca, Locarno, CH for providing access to a number of paintings by Filippo Franzoni for study and SwissRe for financial support.

\section{Competing interests}

The authors declare that they have no competing interests.

Received: 24 October 2014 Accepted: 24 June 2015

Published online: 23 July 2015

\section{References}

1. Ferreira ESB, Boon JJ, van der Horst J, Scherrer NC, Marone F, Stampanoni M (2009) 3D synchrotron X-ray microtomography of paint samples. In: Pezzati L, Salimbeni R (eds) O3A: optics for arts, architecture, and archaeology II. Proceedings of SPIE 2009, vol 7391, 73910L. doi:10.1117/12.827511

2. Ferreira ESB, Boon JJ, Marone F, Stampanoni M (2011) Study of the mechanism of formation of calcium soaps in an early 20th century easel painting with correlative 2D and 3D microscopy. In: Proceeding of 16th Triennial meeting ICOM committee for conservation. James \& James Publisher, Lisbon, September 2011

3. Gervais C, Boon JJ, Marone F, Ferreira ESB (2013) Characterisation of porosity in a 19th century painting by synchrotron radiation $\mathrm{X}$-ray tomography. Appl Phys A 111(1):31-38. doi:10.1007/s00339-012-7533-y

4. Schiessl U (1983) Techniken der Fassmalerei in Barock und Rokoko. Werner'sche Verlaggesellschaft mbH, Worms, Germany, p 63

5. Selvaraj S, Ponmariappan S, Natesan M, Palaniswamy N (2003) Dezincification of brass and its control-an overview. Corros Rev 2(1):41-72
6. Keune K, Boon JJ (2007) Analytical imaging studied of cross sections of paintings affected by lead soap aggregate formation. Stud Conserv 52(3):161-176

7. Robinet L, Corbeil MC (2003) The characterisation of metal soaps. Stud Conserv 48(1):23-40

8. Neufeld AK, Cole IS, Bond AM, Furman SA (2002) The initiation mechanims of corrosion of zinc by sodium chloride particle deposition. Corros Sci 44:555-572

9. Abd El Aal EE (2004) On the pitting corrosion currents of zinc by chloride anions. Corros Sci 46:37-49

10. Scott D (2002) Copper and bronze in art. Getty Publications, Los Angeles

11. Werner U, Selwyn LS, Stone T, McKinnon WR, MacKay A, Grant T (2012) The removal of metal soaps from brass beads on a leather belt. Stud Conserv 57(1):3-20

12. Stambolov T (1985) The corrosion and conservation of metallic antiquities and works of art. Central Research Laboratory for Objects of Art and Science, Amsterdam

13. Meloni S, Salazyr-Walsh M, Haswell, Toussat C (2014) Golden paintings for the golden room of the mauritshuis? The use of SEM-EDX elemental mapping to characterise the use of metal leaf and its degradation in six flower tondos from the golden room of the Mauritshuis. In: $\mathrm{ChemCH}$ 2014 3rd International congress Chemistry for cultural heritage. Book of Abstracts, p 147. http://www.chemch2014.org/BoA.html. Consulted April 2015

14. Stampanoni M, Groso A, Isenegger G, Mikuljan G, Chen Q, Bertrand A et al (2006) Trends in synchrotron-based tomographic imaging: the SLS experience. In: Developments in X-ray tomography V. Proceedings of SPIE 2006, vol 6318,63180M, pp U199-U212. doi:10.1117/12.679497

15. Marone F, Stampanoni M (2012) Regridding reconstruction algorithm for real-time tomographic imaging. J Synchrotron Radiat 19:1029-1037

\section{Publish with ChemistryCentral and every scientist can read your work free of charge \\ "Open access provides opportunities to our colleagues in other parts of the globe, by allowing anyone to view the content free of charge."}

W. Jeffery Hurst, The Hershey Company.

- available free of charge to the entire scientific community

- peer reviewed and published immediately upon acceptance

- cited in PubMed and archived on PubMed Central

- yours - you keep the copyright

Submit your manuscript here:

http://www.chemistrycentral.com/manuscript/ 